\title{
Color Stability and Surface Roughness of Hybrid and Nanofilled Composites Brushed with Abrasive Dentifrices
}

\section{Estabilidade de Cor e Rugosidade Superficial de Resinas Compostas Micro-Híbridas e Nanoparticulada Submetidas à Escovação com Dentifrícios Abrasivos}

\author{
Guilherme Ortiz Pinto da Cruz ${ }^{\mathrm{a}}$; Larissa Martins da Costa ${ }^{\mathrm{b}}$; Cesar Penazzo Lepri品; Ruchele Dias Nogueira ${ }^{\mathrm{a}}$; Regina \\ Guenka Palma-Dibb ${ }^{\text {b }}$ Vinicius Rangel Geraldo-Martins*a
}

\begin{abstract}
${ }^{a}$ Universidade de Uberaba, Faculdade de Odontologia, Department of Clinical Dentistry. SP, Brazil.

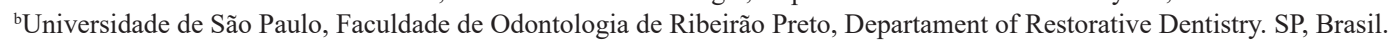
*E-mail: vinicius.martins@uniube.br
\end{abstract}

\begin{abstract}
The aim of this study was to evaluate the color stability and the surface roughness of different composites brushed with toothpastes presenting different levels of abrasivity. Thirty discs of each material were obtained using michohybrid composites (Brilliant NG and Charisma Diamond) and a nanocomposite (Filtek Z350XT). The initial color (CIELab) and surface roughness (confocal laser scanning microscopy) of resin discs were evaluated. Afterwards, 10 specimens per group were brushed with the following dentifrices: Maximum Cavity Protection, Sensodyne Repair \& Protect and Colgate Sensitive Pro-Relief. Brushing was performed with an electric toothbrush equipped with soft bristle head, with standard power and weight, for 30 minutes. Every 30 seconds, $1.0 \mathrm{ml}$ of the slurry was injected between the bristles of the brush and the specimen. After abrasive challenge, the samples had their color and roughness reevaluated. Data were submitted to the Kruskal-Wallis test (color change) or the t-test (surface roughness). The level of significance was $5 \%$. Results: Brushing did not significantly change the color of the composites tested in the study herein. On the other hand, the surface roughness of the composites was significantly affected by the abrasive challenge, regardless of the toothpaste used. The surface roughness change was similar for all the composites. The abrasive challenge with the toothpastes Maximum Cavity protection, Sensodyne Repair \& Protect and Colgate Sensitive Pro-Relief was not able to significantly change the color of the composite resins. Nevertheless, the abrasive challenges significantly altered the surface roughness of all the evaluated composites. However, the changes in surface roughness were statistically similar in the microhybrid and nanofilled composites.
\end{abstract}

Keywords: Composites Resins. Dentifrices. Color.

\section{Resumo}

O objetivo deste estudo foi avaliar a estabilidade de cor e a rugosidade superficial de diferentes resinas compostas escovadas com dentifrícios de diferentes niveis de abrasividade. Trinta discos de cada material foram obtidos utilizando compósitos micro-híbridos (Brilliant NG e Charisma Diamond) e um nanocompósito (Filtek Z350XT). A cor inicial (CIELab) e a rugosidade superficial (microscopia confocal de varredura a laser) dos discos de resina foram avaliadas. Em seguida, 10 amostras por grupo foram escovadas com os dentifrícios Máxima Proteção Anticáries, Sensodyne Repair \& Protect e Colgate Sensitive Pro-Alivio. A escovação foi realizada com uma escova elétrica com cabeça de cerdas macias, com potência e peso padronizados, durante 30 minutos. A cada 30 segundos, 1,0 ml da pasta era injetada entre as cerdas da escova e a amostra. Após o desafio abrasivo, as amostras tiveram sua cor e rugosidade reavaliadas. Os dados foram submetidos ao teste de Kruskal-Wallis (alteração de cor) ou ao teste t (rugosidade da superficie) $(\alpha=5 \%)$. A escovação não alterou significativamente a cor dos compósitos. Por outro lado, a rugosidade superficial dos compósitos foi significativamente afetada pelo desafio abrasivo, independentemente do dentifrício utilizado. A alteração da rugosidade superficial foi semelhante para todos os compósitos. O desafio abrasivo com a Máxima Proteção Anticáries, o Sensodyne Repair \& Protect e o Colgate Sensitive Pro-Alívio não foi capaz de alterar significativamente a cor das resinas. Diferentemente, os desafios abrasivos alteraram significativamente a rugosidade superficial de todos os compósitos avaliados. No entanto, as mudanças na rugosidade foram estatisticamente semelhantes nos compósitos micro-híbridos e nanoparticulado.

Palavras-chave: Resinas Compostas. Dentifrícios. Cor.

\section{Introduction}

Dentin hypersensitivity is a sharp and intense short duration tooth pain condition that affects millions of people nowadays. It appears after the exposition of cervical dentin to the oral environment, as a result of physiological or pathological recession of the gingival margin, after periodontal or orthodontic treatment and inadequate dental brushing technique. ${ }^{1}$ According to the hydrodynamic theory, the sensitivity trigger occurs when electrical, thermal, mechanical, tactile or osmotic stimuli induce fluid movements in the dentin tubules. These fluid movements stimulate the pulp by activating mechanoreceptors of nerves located at the inner ends of the tubules or in the outer layers of the pulp. ${ }^{2}$ Several minimally or non-invasive treatments have been proposed to eliminate the dentin hypersensitivity symptoms, such as the application of fluoride compounds and other desensitizing agents (such as potassium nitrate), the application of high and low intensity lasers and the use of abrasive dentifrices. ${ }^{1,3}$

Among the mentioned treatments, the use of desensitizing toothpaste is the most recommended method by dentists, due to its low cost, ease way of application and rapid relief effect. ${ }^{4}$ 
According to the literature, patients are recommended to brush their teeth with these dentifrices 2 to 3 times daily during 4 to 8 weeks. ${ }^{5}$ Those compounds present a complex formulation with several ingredients considered as desensitizers, such as arginine, strontium chloride, potassium nitrate, sodium fluoride, sodium monofluorophosphate and stannous fluoride. ${ }^{6}$ The action mechanism of dentifrices with desensitizing properties is based on the dentin tubules obliteration by the minerals precipitation over their exposed surface. ${ }^{4,6,7}$ Therefore, many dentifrices contain abrasive particles, such as calcium carbonate, aluminum, calcium phosphate, silicates, which causes an obliteration of the dentinal tubules by abrasiveness or by the formation of a smear layer during brushing. ${ }^{7}$ In the same way that these abrasive agents lead to the root dentin precipitation, they are also likely to change the physical properties of the restorative materials that are present in the oral cavity.

The most used dental material for direct restorations is composite resin, mainly microhybrid and nanofilled composites. ${ }^{8}$ The filler size is one of the determining factors for the most clinically relevant surface properties, such as smoothness and gloss. Past studies showed that nanoparticles were incorporated into resin composite to reduce interparticle space, which would protect the resin matrix. This would result in reduced "plucking" of filler particles from the material surface. ${ }^{9,10}$ It was reported that nanofilled composites have the mechanical strength of a microhybrid composite, but at the same time it maintains smoothness during its clinical use as a microparticles composite. ${ }^{11}$ On the other hand, higher sorption and solubility values were found for nanocomposites compared to hybrid composites, and these might influence their clinical performance. ${ }^{9}$

Therefore, there is still no consensus in the literature on the superiority of the physical properties of the nanofilled composites when compared to the hybrid composites. Therefore, the objectives of the present study were to evaluate the color stability and the surface roughness of different composites subjected to brushing with toothpastes that present different levels of abrasivity. The null hypothesis is that the roughness and the color of the composite are not changed after abrasive challenge.

\section{Material and Methods}

\subsection{Sample preparation}

The composite resins (Table 1) were manipulated following the manufacturers' instructions. Each material was inserted into the cylindrical stainless steel metal mold (6.0 $\mathrm{mm}$ diameter $\times 2.0 \mathrm{~mm}$ thickness) in one increment with an appropriate instrument to obtain 30 discs of each composite. Immediately after insertion of the material, a polyester strip and a glass slide were placed over the mold/resin under axial load of $500 \mathrm{~g}$ for 1 minute to obtain a flat surface. The composite was light cured for $20 \mathrm{~s}$, according to the manufacturer's instructions, using a visible light-curing unit with 1,200 mW/ $\mathrm{cm}^{2}$ power output (Radii-cal, SDI Limited, Bayswater, VIC, Australia). The surfaces opposite to the glass slide were finished and polished with Sof-Lex Pop on sequential discs (3M ESPE, St Paul, MN, USA) from the coarsest to the finest granulation. To standardize the color and surface roughness analyses, a small identification was carried out at the bottom of the specimen, so the measurements could be done always in the same position. Prior to the baseline measurements, the specimens were washed with distilled water for 30 seconds, dried with absorbent paper and immersed in artificial saliva at $37^{\circ} \mathrm{C}$.

Table 1 - Composition of materials used in this study*

\begin{tabular}{|c|c|c|c|}
\hline \multirow[b]{2}{*}{ Composite } & \multicolumn{3}{|c|}{ Composition } \\
\hline & Matrix & $\begin{array}{c}\text { Filler } \\
\text { Size }\end{array}$ & $\begin{array}{c}\text { Filler Load } \\
\text { (weight/ } \\
\text { volume) }\end{array}$ \\
\hline $\begin{array}{c}\text { Brilliant }{ }^{\mathrm{TM}} \mathrm{NG} \\
\text { (A3) } \\
\text { (Lot:1302241) }\end{array}$ & $\begin{array}{c}\text { Bis-GMA, } \\
\text { Bis-EMA, } \\
\text { TEGDMA, } \\
\text { EDAB } \\
\end{array}$ & $\begin{array}{c}0.1-2.5 \\
\mu \mathrm{m}\end{array}$ & $80 \% / 65 \%$ \\
\hline $\begin{array}{c}\text { Charisma } \\
\text { Diamond (A3) } \\
\text { (Lot:010055) }\end{array}$ & $\begin{array}{l}\text { TCD-DI-HEA, } \\
\text { UDMA }\end{array}$ & $\begin{array}{l}5 \mathrm{~nm}- \\
20 \mu \mathrm{m}\end{array}$ & $81 \% / 64 \%$ \\
\hline $\begin{array}{c}\text { Filtek Z350 XT } \\
\text { (A3) } \\
\text { (Lot:955827) }\end{array}$ & $\begin{array}{c}\text { Bis-GMA, } \\
\text { UDMA, } \\
\text { TEGDMA, BIS- } \\
\text { EMA, PEGDMA }\end{array}$ & $\begin{array}{c}20- \\
75 \mathrm{~nm}\end{array}$ & $78.5 \% / 63.3 \%$ \\
\hline
\end{tabular}

*Product information according to the manufacturers (BIS-EMA, bisphenol A-polyethylene glycol diether dimethacrylate; BIS-GMA, bisphenol A-glycerolate dimethacrylate; EDAB, ethylamine benzoate, PEGDMA, polyethylene glycol dimethacrylate; TEGDMA, tetraethylene glycol dimethacrylate; UDMA, urethane dimethacrylate.)

Source: Research data.

\subsection{Baseline analysis}

Samples were divided in 9 groups. Groups 1, 2 and 3 had Brilliant $^{\mathrm{TM}} \mathrm{NG}$ (Coltène/Whaledent Inc., Cuyahoga Falls, $\mathrm{OH}$, USA) discs, Groups 4, 5 and 6 had Charisma Diamond (Heraeus Kulzer, Hanau, Germany) samples and Groups 7, 8 and 9 had Filtek Z350 XT (3M ESPE, St Paul, MN, USA) discs. The baseline surface roughness measurements were assessed using a 3D Laser Confocal Microscope (LEXT 4000, Olympus Co., Hamburg, Germany) at a magnification of $40 \times$. All data were documented at a resolution of $1024 \times 1024$ pixels. The specimens baseline color was measured using the CIE-Lab color system, which is defined as a 3-dimensional (3D) measurement system. In this system, "L" indicates the brightness, "a" the red-green, and "b" the yellow-blue proportion of the color. Three measurements were done with the spectrophotometer active point in the center of each specimen to obtain a mean of each specimen. Before testing, the colorimeter (Color guide 45/0, PCB 6807 BYK-Gardner $\mathrm{GmbH}$, Gerestsried, Germany) was calibrated with a specified calibration plate. 


\subsection{Abrasive challenge}

The composite discs were allocated in twelve groups, according to the dentifrice used (Table 2) $(n=10)$. Groups 1, 4 and 7 were brushed with Colgate Cavity Protection (Colgate Oral Pharmaceuticals, New York, USA), Groups 2, 5, and 8 were brushed with Sensodyne Repair \& Protect (GlaxoSmithKline plc. Brentford, Middlesex-TW United Kingdom), and Groups 3, 6 and 9 were brushed with Colgate Sensitive PRO-Relief (Colgate Oral Pharmaceuticals). Each composite disc was brushed at standardized abrasion force (1.96 $\mathrm{N})$. The dentifrice slurries were made immediately before use and consisted of 1-part dentifrice $(100 \mathrm{ml})$ to 2-parts distilled water $(200 \mathrm{ml})$ and hand-mixed for $2 \mathrm{~min}$, following ISO \#14569-1 specification. An automatic tooth brushing device (Oral-B Pro 5000, Procter and Gamble, Cincinnati, OH, USA) with standardized soft bristled toothbrushes (Oral-B Precision Clean, Procter and Gamble) was used. Each composite disc was brushed for 1800 seconds. Considering that a person brushes each tooth 3 times a day during 5 seconds on each face of the tooth, the present brushing protocol simulated 120 days of toothbrushing. ${ }^{12,13}$ During the abrasive challenge, $1.0 \mathrm{ml}$ of the respective slurry was injected sideways to the specimen every 30 seconds, between the restorative material and the toothbrush. At the final of the abrasive challenge, the composite discs were cleaned in an ultrasonic cleaner device for 1 minute.

Table 2 - Composition of dentifrices used in this study*

\begin{tabular}{|c|c|c|c|}
\hline Groups & Dentifrice & Composition & RDA \\
\hline $\begin{array}{c}1,4 \\
\text { and } 7\end{array}$ & $\begin{array}{l}\text { Colgate Cavity } \\
\text { Protection } \\
\text { (L3290CO1014) }\end{array}$ & $\begin{array}{c}\text { Sodium } \\
\text { Monofluorophosphate, } \\
\text { Dicalcium Phosphate } \\
\text { Dihydrate, Water, } \\
\text { Glycerin, Sodium Lauryl } \\
\text { Sulfate, Cellulose Gum, } \\
\text { Flavor, Tetrasodium } \\
\text { Pyrophosphate, Sodium } \\
\text { Saccharin }\end{array}$ & 70 \\
\hline $\begin{array}{c}2,5 \\
\text { and } 8\end{array}$ & $\begin{array}{c}\text { Sensodyne } \\
\text { Repair \& Protect } \\
(164 \mathrm{EO} 316)\end{array}$ & $\begin{array}{c}\text { Stannous fluoride, } \\
\text { Glycerin, PEG- } 8 \text {, hydrated } \\
\text { silica, pentasodium } \\
\text { triphosphate, sodium } \\
\text { lauryl sulfate, flavor, } \\
\text { titanium dioxide, } \\
\text { polyacrylic acid, } \\
\text { cocamidopropyl betaine, } \\
\text { sodium saccharin }\end{array}$ & 102 \\
\hline $\begin{array}{c}3,6 \\
\text { and } 9\end{array}$ & $\begin{array}{c}\text { Colgate } \\
\text { Sensitive } \\
\text { PRO-Relief } \\
(4164 B R 123 C)\end{array}$ & $\begin{array}{l}\text { Arginine } 8 \% \text {, Calcium } \\
\text { Carbonate, Aqua, Sorbitol, } \\
\text { Bicarbonate, Sodium } \\
\text { Lauryl Sulfate, Sodium } \\
\text { Monofluorophosphate } \\
\text { (1450 ppm F), Aroma, } \\
\text { Cellulose Gum, Sodium } \\
\text { Bicarbonate, Tetrasodium } \\
\text { Pyrophosphate, Titanium } \\
\text { Dioxide, Benzyl Alcohol, } \\
\text { Sodium Saccharin, } \\
\text { Xanthan Gum, Limonene. }\end{array}$ & 81 \\
\hline
\end{tabular}

\subsection{Final Surface roughness and color change analyses}

The surface roughness of each specimen was evaluated at the end of the brushing challenge under the same conditions described for the baseline roughness analysis. The baseline and the final analysis were made exactly at the same position and area. The response variable was the difference between the baseline and the final surface roughness ( $\mathrm{Sf}-\mathrm{Si}$ ).

The final color analysis was done with the same colorimeter used for the baseline measurement. The color difference $(\Delta \mathrm{E})$ between the color coordinates was calculated by applying the formula $\Delta \mathrm{E}^{*}=\left[\left(\Delta \mathrm{L}^{*}\right)^{2}+\left(\Delta \mathrm{a}^{*}\right)^{2}+\left(\Delta \mathrm{b}^{*}\right)^{2}\right]^{1 / 2}$ in order to compare the values before and after the abrasive challenge. Three measurements were done, with the spectrophotometer active point in the center of each specimen to obtain a mean of each specimen. As for the surface roughness measurement, the baseline and the final analysis were made exactly at the same position and area.

\subsection{Statistical analyzes}

The data were tabulated and subjected to statistical analysis (Sigmastat 3.01, Systat, USA). The color change was analyzed by the Kruskal-Wallis test. The differences between the initial and final surface roughness of each composite were compared using the Student's t-test for the related samples. The 2-way ANOVA test was used to compare the mean surface roughness variation obtained in all the groups. The level of significance adopted in all the cases was set at $5 \%$.

\section{Results and Discussion}

The color differences $(\Delta \mathrm{E})$ obtained in each group are shown in Table 3. The effects of each dentifrice on a specific composite resin were analyzed, as well as the comparison among the effects of the same dentifrice on the different composites studied. According to the statistical analysis, the dentifrices used promoted similar color changes in all the composites tested, and all color differences were below 3.3. Thus, the composites color changes at the end of the abrasive challenge have remained within the clinically acceptable range.

Table 3 - Mean ( \pm standard deviation) of the color change $(\Delta \mathrm{E})$ observed in the experimental groups $(\mathrm{p}>0.05)$. The capital letters compare the lines and the lowercase letters compare the columns

\begin{tabular}{|c|c|c|c|}
\hline & \multicolumn{3}{|c|}{$\Delta \mathrm{E}$} \\
\hline & Brilliant NG & $\begin{array}{c}\text { Charisma } \\
\text { Diamond }\end{array}$ & $\mathrm{Z} 350$ \\
\hline $\begin{array}{c}\text { Colgate Cavity } \\
\text { Protection }\end{array}$ & $\begin{array}{c}2.07( \pm 0.86) \\
\mathrm{A}, \mathrm{a}\end{array}$ & $\begin{array}{c}1.87( \pm 0.50) \\
\mathrm{A}, \mathrm{a}\end{array}$ & $\begin{array}{c}1.62( \pm 0.42) \\
\mathrm{A}, \mathrm{a}\end{array}$ \\
\hline $\begin{array}{c}\text { Sensodyne } \\
\text { Repair \& Protect }\end{array}$ & $\begin{array}{c}3.28( \pm 1.23) \\
\mathrm{A}, \mathrm{a}\end{array}$ & $\begin{array}{c}1.58( \pm 0.79) \\
\mathrm{A}, \mathrm{a}\end{array}$ & $\begin{array}{c}2.82( \pm 2.10) \\
\mathrm{A}, \mathrm{a}\end{array}$ \\
\hline $\begin{array}{c}\text { Colgate } \\
\text { Sensitive PRO- } \\
\text { Relief }\end{array}$ & $\begin{array}{c}3.17( \pm 2.27) \\
\mathrm{A}, \mathrm{a}\end{array}$ & $\begin{array}{c}1.44( \pm 1.01) \\
\text { A,a }\end{array}$ & $\begin{array}{c}1.79( \pm 0.49) \\
\mathrm{A}, \mathrm{a}\end{array}$ \\
\hline
\end{tabular}

Source: Research data.

The specimens initial (Sai) and final (Saf) surface roughness after the abrasive challenge are shown in Table 4. 
In all the groups, there was a significant increase in surface roughness after abrasive challenge $(\mathrm{p}<0.05)$.

Table 4 - Mean values of the initial (Sai) and final (Saf) surface roughness of the experimental groups $(\alpha=5 \%)^{*}$

\begin{tabular}{|c|c|c|c|c|c|}
\hline Groups & Dentifrice & $\begin{array}{c}\text { Sai } \\
(\mu \mathrm{m})\end{array}$ & Saf $(\mu \mathrm{m})$ & $\mathbf{t}$ & $\mathbf{p}$ \\
\hline 1 & $\begin{array}{c}\text { Colgate } \\
\text { Cavity } \\
\text { Protection }\end{array}$ & $\begin{array}{c}6.40 \\
( \pm 0.30)\end{array}$ & $\begin{array}{c}6.61 \\
( \pm 0.21)\end{array}$ & -1.974 & 0.0398 \\
\hline 2 & $\begin{array}{l}\text { Sensodyne } \\
\text { Repair \& } \\
\text { Protect }\end{array}$ & $\begin{array}{c}6.42 \\
( \pm 0.16)\end{array}$ & $\begin{array}{c}7.05 \\
( \pm 0.39)\end{array}$ & -6.156 & $\begin{array}{c}< \\
0.0001\end{array}$ \\
\hline 3 & $\begin{array}{c}\text { Colgate } \\
\text { Sensitive } \\
\text { PRO-Relief }\end{array}$ & $\begin{array}{c}6.50 \\
( \pm 0.15)\end{array}$ & $\begin{array}{c}6.92 \\
( \pm 0.36)\end{array}$ & -3.112 & 0.0062 \\
\hline 4 & $\begin{array}{c}\text { Colgate } \\
\text { Cavity } \\
\text { Protection }\end{array}$ & $\begin{array}{c}6.58 \\
( \pm 0.08)\end{array}$ & $\begin{array}{c}7.01 \\
( \pm 0.50)\end{array}$ & -3.090 & 0.0051 \\
\hline 5 & $\begin{array}{l}\text { Sensodyne } \\
\text { Repair \& } \\
\text { Protect }\end{array}$ & $\begin{array}{c}6.58 \\
( \pm 0.10)\end{array}$ & $\begin{array}{c}7.17 \\
( \pm 0.30)\end{array}$ & -6.095 & $\begin{array}{c}< \\
0.0001\end{array}$ \\
\hline 6 & $\begin{array}{c}\text { Colgate } \\
\text { Sensitive } \\
\text { PRO-Relief }\end{array}$ & $\begin{array}{c}6.57 \\
( \pm 0.31)\end{array}$ & $\begin{array}{c}7.27 \\
( \pm 0.31)\end{array}$ & -5.38 & $\begin{array}{c}< \\
0.0001\end{array}$ \\
\hline 7 & $\begin{array}{c}\text { Colgate } \\
\text { Cavity } \\
\text { Protection }\end{array}$ & $\begin{array}{c}7.34 \\
( \pm 0.09)\end{array}$ & $\begin{array}{c}8.11 \\
( \pm 0.35)\end{array}$ & -7.187 & $\begin{array}{c}< \\
0.0001\end{array}$ \\
\hline 8 & $\begin{array}{c}\text { Sensodyne } \\
\text { Repair \& } \\
\text { Protect }\end{array}$ & $\begin{array}{c}7.34 \\
( \pm 0.19)\end{array}$ & $\begin{array}{c}8.21 \\
( \pm 0.38)\end{array}$ & -6.980 & $\begin{array}{c}< \\
0.0001\end{array}$ \\
\hline 9 & $\begin{array}{c}\text { Colgate } \\
\text { Sensitive } \\
\text { PRO-Relief }\end{array}$ & $\begin{array}{c}7.58 \\
( \pm 0.15)\end{array}$ & $\begin{array}{c}8.22 \\
( \pm 0.40)\end{array}$ & -6.131 & $\begin{array}{c}< \\
0.0001\end{array}$ \\
\hline
\end{tabular}

*Composites: Brilliant ${ }^{\mathrm{TM}} \mathrm{NG}$ (Groups 1, 2 and 3); Charisma Diamond (Groups 4, 5 and 6) and Filtek Z350 XT (Groups 7, 8 and 9).

Source: Research data.

Table 5 shows the comparison among the surface roughness variations $(\Delta \mathrm{Sa})$ in all the experimental groups. First, a comparison was made among the roughness variations caused by each dentifrice. The composites subjected to brushing with the dentifrices Colgate Cavity Protection, Sensodyne Repair $\&$ Protect and Colgate Sensitive PRO-Relief presented similar surface roughness variation in all the cases. Likewise, when the evaluation occurred among the composites, all of them presented similar $\Delta \mathrm{Sa}$ for all the toothpastes used in the abrasive challenge.

Table 5 - Mean ( \pm standard deviation) of the surface roughness variation $(\Delta \mathrm{Sa})$ observed in the experimental groups. The capital letters compare the lines and the lowercase letters compare the columns

\begin{tabular}{|c|c|c|c|}
\hline & \multicolumn{3}{|c|}{$\Delta \mathrm{Sa}(\mu \mathrm{m})$} \\
\hline & Brilliant NG & $\begin{array}{c}\text { Charisma } \\
\text { Diamond }\end{array}$ & $\mathbf{Z 3 5 0}$ \\
\hline $\begin{array}{c}\text { Colgate Cavity } \\
\text { Protection }\end{array}$ & $\begin{array}{c}0.216( \pm 0.34) \\
\mathrm{Aa}\end{array}$ & $\begin{array}{c}0.421( \pm 0.51) \\
\mathrm{Aa}\end{array}$ & $\begin{array}{c}0.769( \pm 0.37) \\
\mathrm{Aa}\end{array}$ \\
\hline $\begin{array}{c}\text { Sensodyne } \\
\text { Repair \& } \\
\text { Protect }\end{array}$ & $\begin{array}{c}0.632( \pm 0.35) \\
\mathrm{Aa}\end{array}$ & $\begin{array}{c}0.589( \pm 0.32) \\
\mathrm{Aa}\end{array}$ & $\begin{array}{c}0.877( \pm 0.55) \\
\mathrm{Aa}\end{array}$ \\
\hline $\begin{array}{c}\text { Colgate } \\
\text { Sensitive } \\
\text { PRO-Relief }\end{array}$ & $\begin{array}{c}0.423( \pm 0.42) \\
\mathrm{Aa}\end{array}$ & $\begin{array}{c}0.708( \pm 0.43) \\
\mathrm{Aa}\end{array}$ & $\begin{array}{c}0.643( \pm 0.36) \\
\mathrm{Aa}\end{array}$ \\
\hline
\end{tabular}

Source: Research data.
The present study showed that brushing nanofilled or microhybrids composite discs with the dentifrices used here did not promote significant color change in those restorative materials. On the other hand, the three dentifrices changed the composites surface roughness. Thus, the null hypotheses can be refuted for the surface roughness but not for the color change.

Composite restorations present high longevity in the oral cavity if their clinical indications are correct. Microhybrid and nanofilled composites are indicated for anterior and posterior restorations and they are subject to the abrasive challenges caused by dental brushing. Thus, it becomes necessary to study the material performance over time. Mechanical brushing is adequate to simulate in vitro daily oral hygiene procedures. For this, some parameters must be standardized, such as the time, frequency, amount of toothpaste used during brushing and the force applied on the specimen during abrasive challenge. ${ }^{14}$ In the present research, an electric toothbrush was used, with soft bristles and a standard brushing force of $1.96 \mathrm{~N} .{ }^{15}$ The brush head had 3 sets of bristles of different shapes, positioned at different angles and heights. Each specimen was brushed during 30 minutes without interruption, and every 30 seconds a new slurry solution was applied between the specimen and the bristles of the brush. Taking into account that an individual brushes each face of the tooth with an electric toothbrush for about 5 seconds ( 15 seconds/day), the total time simulated here was 120 days. $^{12}$

Two of the three dentifrices studies here are indicated for the treatment of dentin hypersensitivity. Sensodyne ${ }^{\circledR}$ Repair \& Protect has stannous fluoride and calcium sodium phosphosilicate (NovaMin $\left.{ }^{\circledR}\right)$, which is a bioactive ceramic glass composed of minerals that are present in our body and react when they come into contact with the saliva. This chemical reaction releases sodium ions, which increase the $\mathrm{pH}$ so that released calcium and phosphate ions are precipitated on the tooth structure, resulting in the formation of a new crystal of fluoridated apatite. ${ }^{16}$ Colgate Sensitive Pro-Relief contains the Pro-Argin $^{\mathrm{TM}}$ formula, which represents the association of the amino acid arginine with calcium carbonate. It is a bioactive agent that has been developed in the form of polishing paste and dentifrice for the treatment of dentin hypersensitivity, through the buffers formation inside the dentinal tubules, which are stable and resistant to erosive challenges, besides allowing the deposition of high level of calcium, phosphorus, oxygen and carbonate on the dentin surface. ${ }^{17}$

The color change $(\Delta \mathrm{E})$ of the composite resins after the abrasive challenge was evaluated by a digital spectrophotometer using the CIELAB system, one of the most common color measurement systems in dentistry today. Three different intervals are used for distinguishing color differences: $\Delta \mathrm{E}$ values of 1 are regarded as not appreciable by the human eye; $\Delta \mathrm{E}$ values between 1.0 and 3.3 mean that this change is noticeable only by a qualified person (i.e. the color of the composite is clinically acceptable); and $\Delta \mathrm{E}$ values over 3.3 
indicate that the material color change can be easily observed and therefore clinically unacceptable. ${ }^{18}$ The $\Delta \mathrm{E}$ found here in all the groups, after the abrasive challenges, remained under the threshold of 3.3, indicating that brushing was not able to change the organic matrix morphology of the composite to be clinically observed. This is in accordance with previous in situ and in vitro studies, which stated that although there is a luminosity reduction of the composites after brushing with abrasive dentifrices, that alteration is not high enough to change the resin color at all. ${ }^{19,20}$

The chemical composition and structure of the base monomer influences the degree of conversion, water sorption, water solubility, and color stability of the restorative material. Past studies have shown that UDMA-based materials exhibit higher color stability than Bis-GMA-based composites. Likewise, HEMA composites have lower water sorption and higher hardness than Bis-GMA-based monomers. On the other hand, resins with higher amounts of TEGDMA and TTEGMMA monomers present high water sorption. Clinically, a high water sorption may lead to a greater pigments retention on the restorative material surface. ${ }^{21,22}$ Charisma Diamond, for example, presents the monomers UDMA and TCD-DIHEA. Little is known about the performance of the TCD-DIHEA monomer in the degradation process. According to the literature, this monomer provides low shrinkage, low viscosity and higher wear resistance. Furthermore, the presence of UDMA is believed to provide greater hydrolytic stability to the material, which may be enhanced by the presence of TCDDI-HEA, rendering that composite less susceptible to color change. ${ }^{23,24}$

Regarding the filler type, the composites used in this study are classified as microhybrids and nanocomposite. The amount of the materials filler tested here is practically the same ( $80 \%$ by weight and $65 \%$ by volume), which could explain the similar color stability presented by the composites after the abrasive challenges, due to the fact that as the amount of filler particles increases, the amount of organic matrix decreases, decreasing the water sorption, promoting higher color stability. ${ }^{25}$

The samples surface roughness was evaluated by confocal laser scanning microscopy. The surface roughness of a composite is influenced by a number of factors, such as the filler particles size, the percentage of surface area filled by the inorganic particles, the hardness, the composite degree of conversion and the interaction between the organic and inorganic matrices. ${ }^{26}$

One of the goals of toothbrushing is to polish teeth and restorations superficially to achieve surfaces that are smoother and less susceptible to staining. Since completely flat restorations cannot be achieved, such procedures can have a direct influence on the restoration longevity. ${ }^{15}$ In the present research the abrasive challenge altered the final surface roughness of all the composites used, which is in agreement with past studies. ${ }^{15,27}$

The dentifrices abrasivity is measured by the relative dentin abrasivity (RDA), which is the abrasivity of a dentifrice in relation to a standard paste set at 100 . RDA is a reasonably robust method considered a useful tool for the determination of the relative abrasive level of dentifrices and abrasive powders. ${ }^{7}$ RDA ranges from 0 to 250 , and low abrasive dentifrices have RDAs between 0-70, medium abrasive have RDAs of 71-100, high abrasives have RDAs of 101-150, and those considered potentially damaging to dentin have an RDA of 151-250. According to that classification, the dentifrices used here had low (Colgate Cavity Protection), medium (Colgate Sensitive Pro-relief) and high (Sensodyne Repair \& Protect) abrasiveness. ${ }^{7,17}$

The dentifrices of lower abrasiveness are gel toothpastes containing silica as their abrasive agent. However, when silica is combined with other abrasives, such as calcium carbonate, sodium pyrophosphate, titanium oxide or sodium phosphate, it is considered as a high abrasive dentifrice. Silica, when used in fine particles and with regular forms, preserves its characteristic of low abrasive mineral. Nevertheless, when thick and irregular particles are incorporated, the dentifrice becomes highly abrasive. Thus, only the formulation or type of abrasive present in a dentifrice is not sufficient to characterize its abrasiveness to the composites. ${ }^{7}$

According to previous studies, changes in the composite surface roughness after abrasive challenge have been related to the polymer matrix or the matrix/filler interface degradation, and the filler particles release from the resin matrix..$^{25,28}$ Lai et al (2017) said that, in addition to the dentifrice abrasivity, the bristles of the dental brush may cause the composite degradation. Although the softer bristles lead to a lower degradation of the composite surface, the time and the brushing force contribute to alter the restorative material surface. $^{29}$

A scanning electron microscopy study reported that the nanoparticles of the Z350XT composite detached from the organic matrix after automated brushing using low abrasive dentifrice and soft bristle brushes and brushing strength of $0.2 \mathrm{~N}$. The author has suggested that due to their size and regularity, nanoparticles can be more easily removed from the composite surface than larger and irregular filler particles. ${ }^{28}$ Thus, not only the dentifrice abrasivity, but also the brushing dynamics used here explain the roughness changes found in the present research.

A suggestion to improve the composites wear resistance would be to increase the abrasion resistance of the organic matrix, rather than increase the filler particles hardness. The most commonly used monomer in direct composite resins has been Bis-GMA, which, due to its high viscosity, is mixed with other dimethacrylates, such as TEGDMA, in order to control the composite flow. ${ }^{22}$ The urethane dimethacrylate corresponds to an alternate composition of the organic 
matrix. Polyurethane-based composites showed significantly better performance regarding to wear resistance than BisGMA-based composites in more than three years of clinical observation. ${ }^{30}$ Even though little information is available about the TCD-DI-HEA monomer present in Charisma Diamond, past studies have suggested that this composite may have higher values of wear resistance than other resins based on Bis-GMA. ${ }^{31-33}$

\section{Conclusion}

According to the results obtained in the present research, the abrasive challenge did not promote significant color changes in the composite. However, brushing with the dentifrices tested here significantly changed the surface roughness of the michohybrid and the nanofilled composites. Nevertheless, it is not known if that increase in surface roughness would be significant to the extent of increasing the pigments or biofilm retention on the surface of those composites, or if the variations in the $\mathrm{pH}$ of the oral cavity allied to brushing would further change the composites smoothness, which would justify additional studies in this area.

\section{Acknowledgements}

The authors deny any conflict of interest related to this study. This work was supported by the Fundação de Amparo à Pesquisa do Estado de Minas Gerais (FAPEMIG \#5.239/15).

\section{References}

1. West N, Seong J, Davies M. Dentine hypersensitivity. Monogr Oral Sci 2014; 25:108-22. doi: 10.1159/000360749

2. Peterson LG. The role of fluoride in the preventive management of dentin hypersensitivity and root caries. Clin Oral Invest 2013;17:S63-S71. doi: 10.1007/s00784-0120916-9

3. Cury MS, Silva CB, Nogueira RD, Campos MGD, PalmaDibb RG, Geraldo-Martins VR. Surface roughness and bacterial adhesion on root dentin treated with diode laser and conventional desensitizing agents. Lasers Med Sci 2018;33(2):257-62. doi: 10.1007/s10103-017-2356-X

4. Clark D, Levin L. Non-surgical management of tooth hypersensitivity. Int Dent J 2016;66(5):249-56. doi: 10.1111/ idj.12247

5. França-Grohmann IL, Sangiorgio JM, Viana Casarin RC, Casati MZ, Sallum AW, Sallum EA. Dentin hypersensitivity reduction using an arginine-based approach after non-surgical periodontal treatment. Am J Dent 2016;29(5):271-6.

6. Addy M, West NX. The role of toothpaste in the aetiology and treatment of dentine hypersensitivity. Monogr Oral Sci 2013;23:75-87. doi: 10.1159/000350477

7. González-Cabezas C, Hara AT, Hefferren J, Lippert F. Abrasivity testing of dentifrices - challenges and current state of the art. Monogr Oral Sci 2013;23:100-7. doi: $10.1159 / 000350476$

8. Silvani S, Trivelato RF, Nogueira RD, Gonçalves Lde S, Geraldo-Martins VR. Factors affecting the placement or replacement of direct restorations in a dental school. Contemp Clin Dent 2014;5(1):54-58. doi: 10.4103/0976-237X.128664
9. Alzraikat H, Burrow MF, Maghaireh GA, Taha NA. Nanofilled Resin Composite Properties and Clinical Performance: A Review. Oper Dent 2018;43(4): E173-E190. doi: 10.2341/17208-T

10. Angerame D, De Biasi M. Do Nanofilled/Nanohybrid Composites Allow for Better Clinical Performance of Direct Restorations Than Traditional Microhybrid Composites? A Systematic Review. Oper Dent 2018;43(4): E191-E209. doi: 10.2341/17-212-L

11. Zakir M, Al Kheraif AA, Asif M, Wong FS, Rehman IU. A comparison of the mechanical properties of a modified silorane based dental composite with those of commercially available composite material. Dent Mater 2013;29(4): e5359. doi: 10.1016/j.dental.2012.12.006

12. Hegde S, Rao BH, Kakar RC, Kakar A. A comparison of dentifrices for clinical relief from dentin hypersensitivity using the Jay Sensitivity Sensor Probe. Am J Dent 2013;26(Spec No B): 29B-36B.

13. Sharma D, McGuire JA, Amini P. Randomized trial of the clinical efficacy of a potassium oxalate-containing mouthrinse in rapid relief of dentin sensitivity. J Clin Dent 2013;24(2):6267.

14. da Costa J, Adams-Belusko A, Riley K, Ferracane JL. The effect of various dentifrices on surface roughness and gloss of resin composites. J Dent 2010;38(2):e123-128. doi: 10.1016/j.jdent.2010.02.005

15. da Silva EM, de Sá Rodrigues CU, Dias DA, da Silva S, Amaral CM, Guimarães JG. Effect of toothbrushingmouthrinse-cycling on surface roughness and topography of nanofilled, microfilled, and microhybrid resin composites. Oper Dent 2014;39(5):521-9. doi: 10.2341/13-199-L

16. Kanwal N, Brauer DS, Earl J, Wilson RM, Karpukhina N, Hill RG. In-vitro apatite formation capacity of a bioactive glass - containing toothpaste. J Dent 2018; 68:51-8. doi: 10.1016/j.jdent.2017.10.015

17. Lopes RM, Turbino ML, Zezell DM, Scaramucci T, Aranha AC. The effect of desensitizing dentifrices on dentin wear and tubule occlusion. Am J Dent 2015;28(5):297-302.

18. Vichi A, Ferrari M, Davidson CL. Color and opacity variations in three different resin-based composite products after water aging. Dent Mater 2004;20(6):530-4. doi: 10.1016/j. dental.2002.11.001

19. Lai G, Zhao L, Wang J, Kunzelmann KH. Surface properties and color stability of dental flowable composites influenced by simulated toothbrushing. Dent Mater J 2018;37(5):717724. doi: 10.4012/dmj.2017-233

20. de Moraes Rego Roselino L, Tonani Torrieri R, Sbardelotto C, Alves Amorim A, Noronha Ferraz de Arruda C, Tirapelli C, de Carvalho Panzeri Pires-de-Souza F. Color stability and surface roughness of composite resins submitted to brushing with bleaching toothpastes: An in situ study. J Esthet Restor Dent 2019;31(5):486-492. doi: 10.1111/jerd.1249

21. Barszczewska-Rybarek IM. Characterization of urethanedimethacrylate derivatives as alternative monomers for the restorative composite matrix. Dent Mater 2014;30(12):133644. doi: 10.1016/j.dental.2014.09.008

22. Fonseca AS, Labruna Moreira AD, de Albuquerque PP, de Menezes LR, Pfeifer CS, Schneider LF. Effect of monomer type on the $\mathrm{CC}$ degree of conversion, water sorption and solubility, and color stability of model dental composites. Dent Mater 2017;33(4):394-401. doi: 10.1016/j. dental.2017.01.010 
23. Alshali RZ, Salim NA, Sung R, Satterthwaite JD, Silikas N. Qualitative and quantitative characterization of monomers of uncured bulk-fill and conventional resin-composites using liquid chromatography/mass spectrometry. Dent Mater 2015;31(6):711-720. doi: 10.1016/j.dental.2015.03.010

24. Marchesi G, Breschi L, Antoniolli F, Di Lenarda R, Ferracane J, Cadenaro M. Contraction stress of low-shrinkage composite materials assessed with different testing systems. Dent Mater 2010;26(10):947-53. doi: 10.1016/j.dental.2010.05.007

25. Roselino L de M, Cruvinel DR, Chinelatti MA, Pires-deSouza Fde C. Effect of brushing and accelerated ageing on color stability and surface roughness of composites. J Dent 2013; 41(5): e54-61. doi: 10.1016/j.jdent.2013.07.005

26. Daud A, Gray G, Lynch CD, Wilson NHF, Blum IR. A randomised controlled study on the use of finishing and polishing systems on different resin composites using 3D contact optical profilometry and scanning electron microscopy. J Dent 2018;71:25-30. doi: 10.1016/j.jdent.2018.01.008

27. Bonato F, Spohr AM, Mota EG, Rodrigues-Junior SA, Burnett LH Jr. Surface roughness and maintenance of surface sealants for resin composites after toothbrushing. Am J Dent 2016; 29(1):39-45.

28. Al Khuraif AA. An in vitro evaluation of wear and surface roughness of particulate filler composite resin after tooth brushing. Acta Odontol Scand 2014;72(8):977-83. doi:

\section{$10.3109 / 00016357.2014 .933251$}

29. Lai G, Zhao L, Wang J, Kunzelmann KH. Surface properties and color stability of incrementally-filled and bulkfill composites after in vitro toothbrushing. Am J Dent 2017;30(5):262-6.

30. Söderholm KJ, Lambrechts P, Sarrett D, Abe Y, Yang MC, Labella R, Yildiz E, Willems G. Clinical wear performance of eight experimental dental composites over three years determined by two measuring methods. Eur J Oral Sci 2001;109(4):273-281. doi: 10.1034/j.16000722.2001.00064.x

31. Cao L, Zhao X, Gong X, Zhao S. An in vitro investigation of wear resistance and hardness of composite resins. Int J Clin Exp Med 2013;26;6(6):423-430.

32. Rosatto CM, Bicalho AA, Veríssimo C, Bragança GF, Rodrigues MP, Tantbirojn D, Versluis A, Soares CJ. Mechanical properties, shrinkage stress, cuspal strain and fracture resistance of molars restored with bulk-fill composites and incremental filling technique. J Dent 2015;43(12):151928. doi: 10.1016/j.jdent.2015.09.007

33. Suzuki T, Kyoizumi H, Finger WJ, Kanehira M, Endo T, Utterodt A, Hisamitsu H, Komatsu M. Resistance of nanofill and nanohybrid resin composites to toothbrush abrasion with calcium carbonate slurry. Dent Mater J 2009;28(6):708-16. doi: $10.4012 / \mathrm{dmj} .28 .708$ 